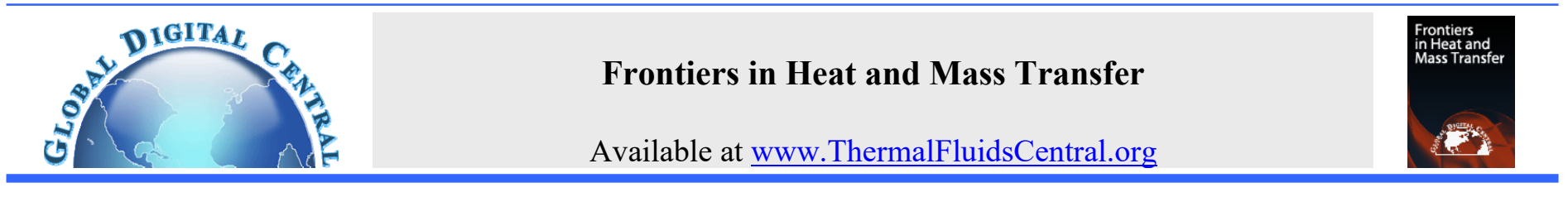

\title{
AN EXPERIMENTAL STUDY ON A NEW HIGH-EFFICIENT SUPERCHARGER FOR SEAWATER REVERSE OSMOSIS DESALINATION DRIVEN DIRECTLY BY TIDAL ENERGY
}

\author{
Changming Ling ${ }^{\mathrm{a}, \mathrm{b}^{* \dagger}}{ }^{\text {, Xiaobo Lou }}{ }^{\mathrm{c}}$, Yin Zhong ${ }^{\mathrm{b}}$ \\ ${ }^{a}$ Southern Marine Science and Engineering Guangdong Laboratory (Zhanjiang), Zhanjiang, Guangdong Province, 524000, China \\ ${ }^{b}$ School of Mechanical and Power Engineering, Guangdong Ocean University, Zhanjiang, Guangdong Province, 524000, China \\ ${ }^{c}$ DongGuan Science \& Technology School, Dongguan, Guangdong Province, 523470, China
}

\begin{abstract}
To solve the issues of high-energetic consumption, high-cost and high-carbon emissions in the processes of reverse osmosis seawater desalination technology, this study proposed and implemented a tidal energy-gathering supercharger with the concept of using green tidal energy to directly produce high-pressure-seawater-driven reverse osmosis seawater desalination system. Compared with the traditional way of using tidal energy to produce electric power in order to produce high-pressure water for the system, this technology could save energy that may lost in two transferring process thus can improve the energy efficiency of the whole system, lower its running cost, and realize the green production concept of zero carbon emission. To study the differences of influences on energy-gathering supercharger caused between two types of tidal energy usage, comparison had been made under conditions of fixed work seawater flow and fixed-work seawater circuit opening adjustment. The results show that compared with the traditional tidal energy-driven electricity generation, adaptive-frequency and high-efficient energy-gathering supercharge experimental system that suits tidal changes can increase the use efficiency of tidal energy, make energy-gathering supercharger absorb more tidal energy thus produce more high-pressure water.
\end{abstract}

Keywords: tidal energy; supercharger; fixed-work seawater flow; fixed-work seawater circuit opening adjustment

\section{INTRODUCTION}

With the development of the economy and expansion of population worldwide, the energy crisis and global warming have emerged. Under such circumstances, globally there is a growing demand for the utilization of renewable clean energy to replace conventional fossil fuels (Falconer et al., 2010). As an example, marine renewable energy has got much interest in recent years as an attractive means of generating low carbon energy considering its abundant availability and strong stability around the world. Subsequently, it can play a key role in replacing conventional fossil fuels (Ahmadian et al., 2013; Gao et al., 2013). It can also alleviate effectively the phenomena of environmental pollution and energy crisis when utilized and developed scientifically (Choon et al., 2015). Meanwhile, the utilization of marine renewable energy can meet the requirements of sustainable development of the human society (An, 2016; Zhang et al., 2012). Evidently, it is shown that among the various marine renewable energies, tidal energy is abundant and one of the new energy sources with the huge potential of sustainable development, and its technology is relatively mature (Zhang, 2011). Some countries worldwide such as the United Kingdom, Russia and China, have already developed some large-scale tidal power stations and put into productions.

However, the tidal energy utilization method is relatively simple, mainly using the power generation technology that converts its stored energy into electric power. The method of combination tidal energy and desalination technology is using the potential energy of tidal energy for desalination. Researches on this coupling method are still in the exploration stage. The urgent demand of seawater reverse osmosis desalination technology on direct electricity and indirect fossil fuels has led to high energy costs and carbon emissions. Some scholars have proposed to use renewable energy to replace fossil fuels for seawater desalination. Liu et al. (Liu and Zhao, 2009; Zhao and Liu, 2009) developed a solar multi-effect distillation seawater desalination device using tidal energy and utilizing the characteristics of tidal energy and solar energy based on the method of multi-effect distillation. This device replaced the electric-drive water and vacuum pumps in the traditional method to provide water supply and drainage through the tidal energy, which provided power for vacuuming, and used green energy instead of electric power to save costs.

So far, the production capacity of the sea-dried desalination technology using electric-drive has reached a daily output of about $8.6 \times 107 \mathrm{~m}^{3}$, of which reverse osmosis desalination technology is in a dominant position, playing an important role in alleviating the water shortage(Peñate and García-Rodríguez ., 2012; Gao et al., 2016).

John (John, 2000) designed a wave energy collection device that applied wave energy to the high-pressure pump directly which could produce the ideal vapor pressure, and delivered the vapor pressure to the reverse osmosis desalination system through an external converter. Kobashikawa and Fok (Kobashikawa and Fok, 2004) designed a wave energy conversion device that applied wave energy process used for pressurizing seawater in a reverse osmosis desalination system. However, little attention had been devoted to seawater reverse osmosis desalination system directly produced by tidal energy. Zheng (Zheng, 2011) analyzed and calculated a variety of tidal energy utilization methods coupled with seawater reverse osmosis desalination scheme,

\footnotetext{
* Southern Marine Science and Engineering Guangdong Laboratory (Zhanjiang), Zhangjiang, Guangdong Province, 524000, China

Corresponding author. Email: ling-cm@,163.com
} 
and proposed tidal energy reverse osmosis desalination scheme. Lei (Lei, 2015) built an experimental platform for the production of highpressure seawater directly to supply pressure to seawater reverse osmosis desalination system, and verified that the method could complete the preparation of $6 \mathrm{MPa}$ high-pressure seawater. Ling et al. (Ling et al., 2011; Ling et al., 2018; Ling et al., 2013) established a framework for producing high-pressure seawater for seawater reverse osmosis desalination by tidal energy directly, without conversion of electric power. Wang et al. (Wang, 2013; Ling et al., 2015) investigated the performance of the seawater reverse osmosis desalination system directly driven by tidal energy which proved the method could directly pressurize the low-pressure seawater into high-pressure seawater through experiments. Comparing the tidal energy directly driving seawater reverse osmosis desalination system with the tidal energy indirectly driving seawater reverse osmosis desalination system after tidal power generation, it was calculated that the energy efficiency of tidal energy directly driving seawater reverse osmosis desalination system was $17.5 \%$ higher than that of indirectly driving seawater reverse osmosis desalination system after tidal power generation. It was hoped that the question will be resolved with our proposed method.

The characteristics of tidal energy technology and seawater reverse osmosis desalination technology were analyzed in the paper, and a device for supplying high pressure seawater to the reverse osmosis seawater desalination system by a supercharger was developed. After many experiments, it has verified about the feasibility of supercharger.

The purpose of this method was replacing fossil fuels to produce fresh water and alleviate the energy and environmental crisis. To study the differences of influences on energy-gathering supercharger caused between two types of tidal energy usage, comparison had been made under conditions of fixed work seawater flow and fixed-work seawater circuit opening adjustment. Simulation of electricity-producing methods adopted using tidal energy. The rule of how energy-gathering supercharger produces high pressure seawater in the circumstances of fixed water flow work was studied because when generates electricity, the flow of seawater done work should be stable in order to keep the dynamo at a rated speed. The flow of seawater that did work needn't be controlled when the tidal energy couldn't be used for electricity generation. Thus, to study the performance index of adaptive-frequency and high-efficient energy-gathering supercharger that suits tidal changes, experiments were carried out in the circumstances of fixedwork seawater circuit opening adjustment.

\section{EXPERIMENTAL BACKGROUND OF SUPERCHARGER}

\subsection{Purpose of Building Experimental Platform}

The costs of reverse osmosis desalination have been high, which aggravate energy crisis and environmental impact in recent years. The reserves of ocean energy are inexhaustible renewable energy. Tidal energy is the most widely used and mature renewable energy source in marine energy. At present, the utilization of tidal energy is mainly concentrated in the field of tidal power generation. In order to meet user's requirement for power stability, it is necessary to control the flow of tidal seawater, which will enable some tidal energy to be fully utilized when electric power is generated by tidal energy. If the tidal energy can be directly utilized and the electric power conversion is not performed, the tidal energy utilization rate can be effectively improved, and the energy loss in the electric power conversion process can be saved. The method of directly producing high-pressure seawater to supply reverse osmosis seawater desalination system by using tidal energy as a power source does not need to control the output work of tidal waves, and can fully utilize the work seawater flow work under any tidal range. In order to investigate the performance of a frequencyadapted high-efficiency supercharger that can adapt to tidal variations, a supercharger test bench was built to conduct relevant experiments. At the same time, the performance of the supercharger is simulated under the condition of controlling the tidal work seawater flow when tidal energy is generated, so as to compare the direct use of tidal energy with the indirect use.

\subsection{Test System}

The main device in this study consisted of a supercharger and its auxiliary device. The process flow chart of tidal energy gathered and seawater pressurized desalination system is shown in Figure 1. The tidal energy can be transmitted to the supercharger to pressurize the filtered low-pressure seawater to obtain high pressure seawater, and the stabilized high-pressure seawater can produce fresh water through the seawater reverse osmosis system. The authors of the article retain the copyright.

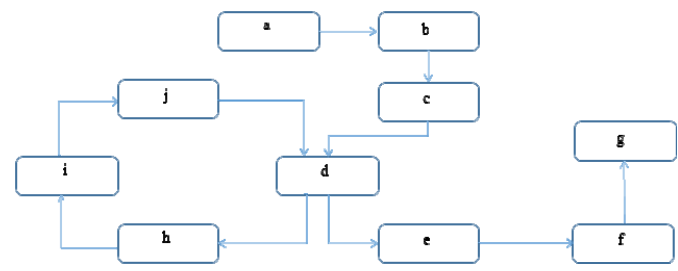

a. low-pressure water; b. mechanical screening device; c. security filter; d. supercharger; e. high-pressure water; f. seawater reverse osmosis system; g. fresh water; h. return water tank; i. immersible pump; j. elevated tank

Fig. 1 Process flow chart of tidal energy gathering and pressurized desalination system

An experimental platform for testing the hydraulic performances of supercharger has been built. The schematic diagram of the experimental system is shown in Figure 2.

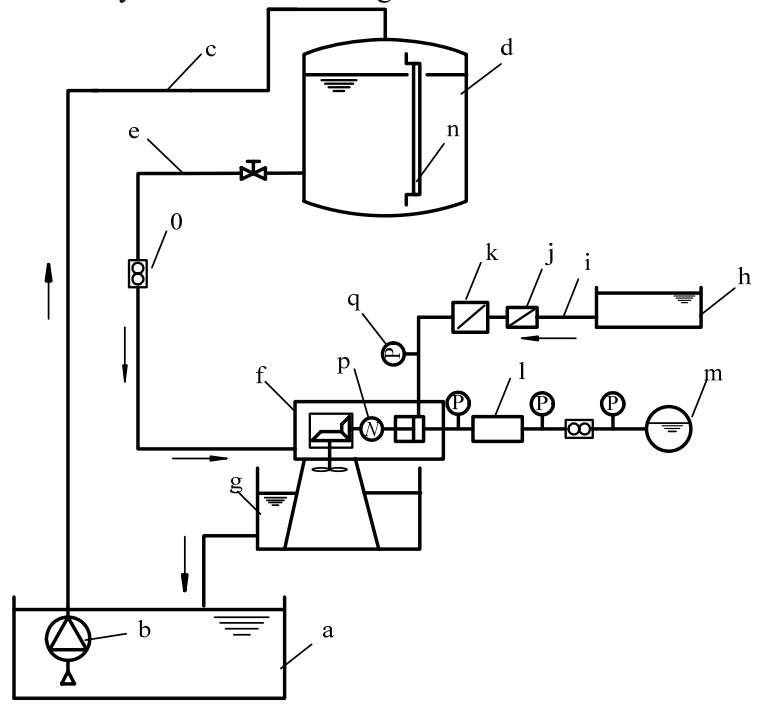

a. return water tank; b. diving pump; c. return water line; d. elevated tank; e. water supply line; f. supercharger; g. drainage tank; h. feed water tank; i. feed water line; j. mechanical filter; k. precision filter; 1. hydraulic pressure regulator; $m$. high-pressure seawater tank; $n$. liquidometer; o. ultrasonic flowmeter; p. torque tachometer; q. pressure gage

Fig. 2 Schematic diagram of tested supercharger system

It works as follows. A hydraulic turbine is driven by tidal range between an elevated tank and a drainage tank to convert water level potential energy into shaft work. A hydraulic pump subsequently obtains the shaft work by a gearbox. A return water tank is used for collecting drainage seawater from the drainage tank, and a diving pump which is connected to the return water tank to pump seawater back to the elevated tank. The seawater from a feed water tank must be treated by a mechanical filter and a precision filter before entering the hydraulic pump, thus reducing the particulate matter in the feed 
seawater. After that, the pressure of feed seawater is raised by the hydraulic pump and achieves a value that is required for the seawater reverse osmosis process.

\subsection{High-Efficient Supercharger}

The core device of this experiment is the high-efficient supercharger. The supercharger system is mainly composed of an energy concentrator and a booster structures. The main function of the supercharger is to convert tidal energy into mechanical shaft work. However, the highefficient supercharger does no longer convert the mechanical shaft work into electric power for storage, but drive the desalination system directly.

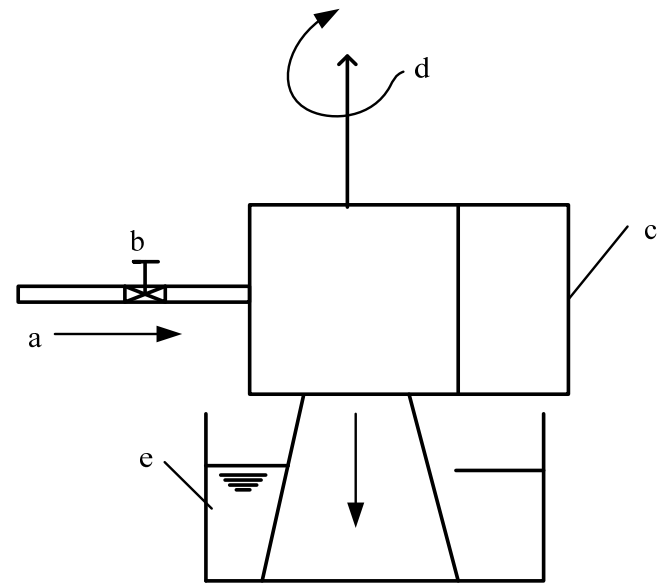

a. work seawater, b. butterfly bamper, c. hydraulic turbine, d. mechanical shaft work, e. drainage tank

Fig. 3 High-efficient supercharger system

The schematic diagram of the supercharger is shown in Figure 3. The work seawater passes through the pipeline and flow into the turbine vortex chamber and through the turbine blades, and then drive the turbine to produce shaft work such that the tidal energy is converted into mechanical energy. Meanwhile, the work seawater discharges to the drainage tank. The produced shaft work will then drive the hydraulic pump to pressurize the low-pressure seawater into highpressure seawater. The change in tidal range causes a change in the work seawater flow, which in turn affects the rotational speed and the power obtained by the concentrator. The concentrator then transmits the rotational speed and power to the supercharger, thereby pressurizing the atmospheric pressure seawater to obtain the high-pressure seawater. By means of this test facility, the boosting pressure was measured up to 6 $\mathrm{MPa}$ (water head $600 \mathrm{~m}$ ), which was 150 times higher than the initial tidal range $4 \mathrm{~m}$ and could meet the requirement of a seawater reverse osmosis desalination system. A picture of the tested supercharger is shown in Figure 4.

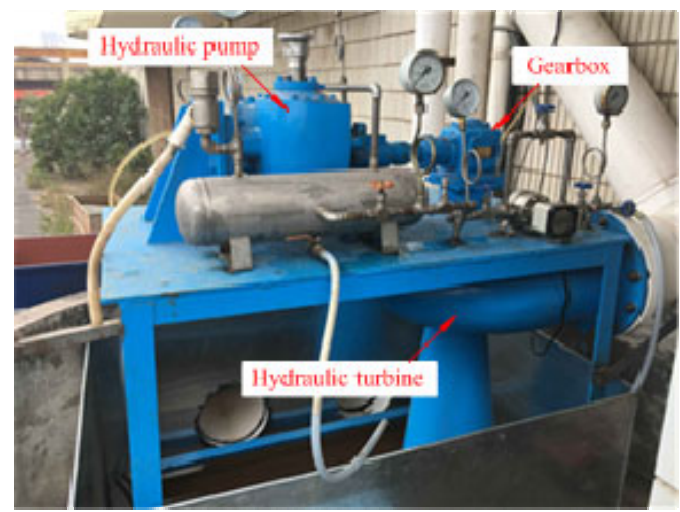

Fig. 4 Tested supercharger

\subsection{Experimental Stability Test}

To ensure the stability of the operation of test bench and the accuracy of experimental data in the process, the reproducibility of the test bench was first tested. The results are shown in Figure 5.
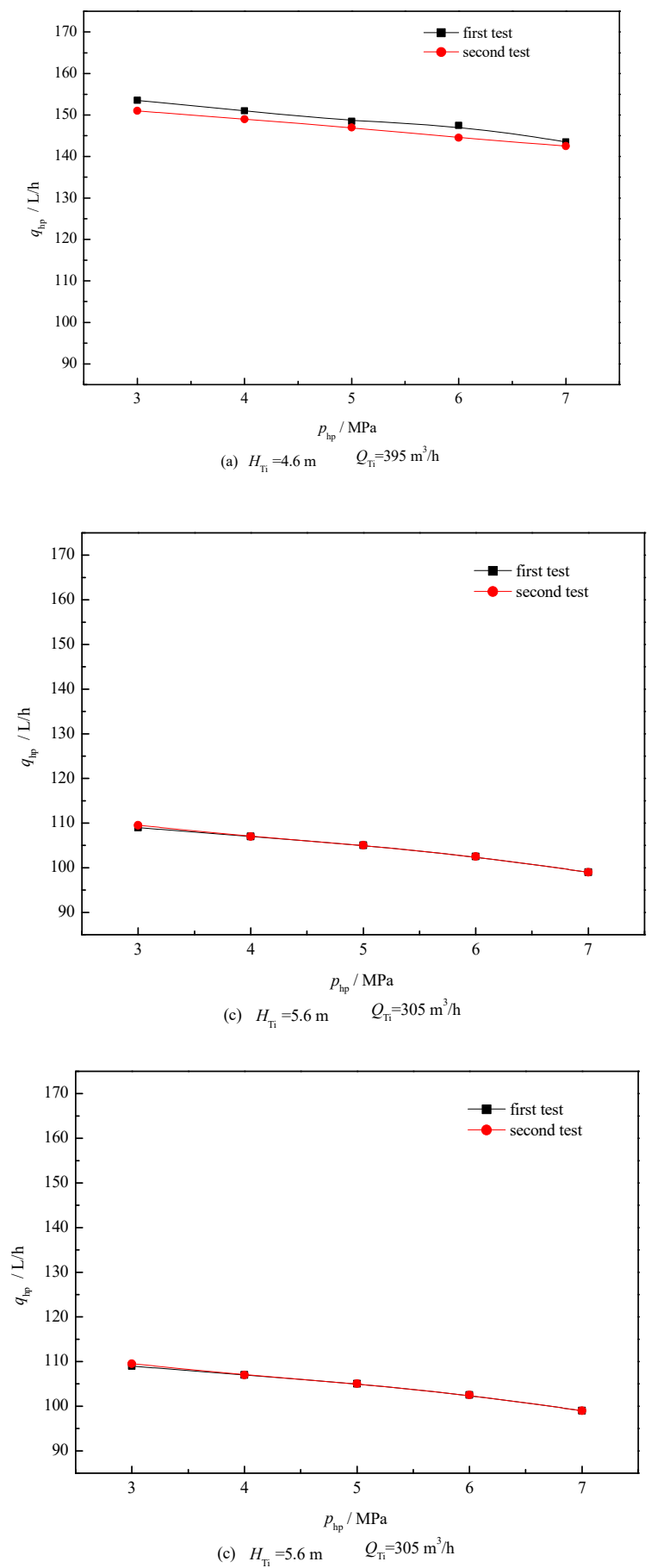

Fig. 5 Reproducibility tests

An reproducibility tests were carried out on the experimental bench. The tidal ranges $H_{T i}$ were selected to be $4.6 \mathrm{~m}, 5.0 \mathrm{~m}$ and $5.6 \mathrm{~m}$, respectively; and the corresponding work seawater flows $Q_{T i}$ were 395 $\mathrm{m}^{3} / \mathrm{h}, 350 \mathrm{~m}^{3} / \mathrm{h}$ and $305 \mathrm{~m}^{3} / \mathrm{h}$, respectively. It was found that when the tidal range is $4.6 \mathrm{~m}$, the reproducibility of the experimental results is slightly worse than the tidal range of $5.0 \mathrm{~m}$ and $5.6 \mathrm{~m}$. According to the construction of the experimental platform, the height of the work water outlet pipe is $4.4 \mathrm{~m}$, and the tidal range is $4.6 \mathrm{~m}$, which is closer to the 
outlet pipe. The fluctuation of the nozzle has a large fluctuation on the tidal liquid level. As shown in Figure 5, the error of the high pressure seawater flow is within $1.00 \%$, which is within the acceptable range. Therefore, it is considered that the reproducibility and stability of the test bench are appropriate to the study, and the performance test of the test bench can be performed.

\section{RESULTS AND DISCUSSION}

When electric power is generated by tidal energy, it is necessary to adjust the vane mechanism opening degree to control the seawater flow rate and output the same electric power under different tidal ranges. Using the supercharger to simulate the tidal work of tidal power generation, the performance of supercharged system under fixed work seawater flow conditions is explored. According to the knowledge of fluid mechanics, if the pipe opening is constant, the change in tidal range will cause a change in the flow of the working seawater. The fixed work seawater flow method needs to adjust the pipeline butterfly valve after stabilizing the tidal range, and control the seawater flow of the work to the required range.

If the tidal energy is not used for power generation, it is not necessary to adjust the governing mechanism of the turbine to control the seawater flow to work. At this time, the opening degree of the pipeline can be fixed, and the seawater can be freely worked under any tidal range. The fixed-work seawater circuit opening adjustment method mainly studies the supercharging performance of the frequencyefficient high-efficient energy-concentration supercharging device under the work conditions of the fixed pipe valve opening.

This paper mainly compares the performance of two types of energy-enhanced supercharging systems, and analyzes the advantages of tidal energy directly producing high-pressure seawater for reverse osmosis seawater desalination.

\subsection{Work Seawater Flow}

Figure 6 shows the variation of the $Q_{T i}$ of the work seawater flow with the tidal range $H_{T i}$ under the two conditions of fixed work seawater flow and fixed-work seawater circuit opening adjustment.

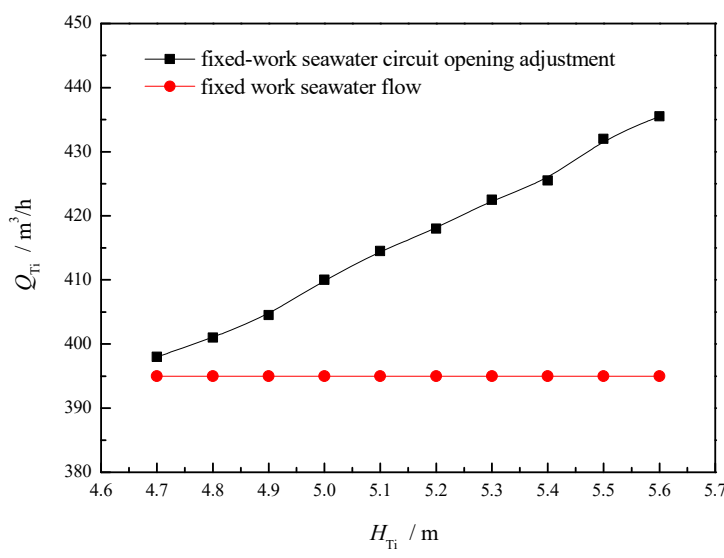

Fig. 6 work seawater flow vs. tidal range

It can be seen from Figure 6 when the tidal range is $4.7 \mathrm{~m}$, the two working conditions have similar seawater flow. When the tidal range is $5.6 \mathrm{~m}$, the working seawater flow rate is $10.25 \%$ more than the fixed work seawater flow under the fixed-work seawater circuit opening adjustment condition. Under fixed work seawater flow conditions, the tidal range no longer affects the work seawater flow; under the fixed working seawater circuit opening condition, the work seawater flow is positively correlated with the tidal range, and increases with the tidal range. As the tidal range increases, when the pipe opening remains unchanged, the kinetic energy of the pipe outlet will gradually increase with the potential energy of tidal range. So, when the fixed work seawater circuit is opened, the work seawater flow increases as the tidal range increases. When the working seawater flow is fixed, it is necessary to adjust the working seawater circuit opening degree to ensure the working seawater flow rate is within the required range under each tidal range.

Therefore, under the same tidal range, compared with the method of producing high-pressure seawater after tidal energy can be generated first, the tidal energy can directly produce high-pressure seawater, and more seawater can work on the condensing supercharger.

\subsection{Input Power of Supercharger}

Figure 7 shows the variation of the input power $P_{l}$ of supercharger with the tidal range $H_{T i}$ under two operating conditions.

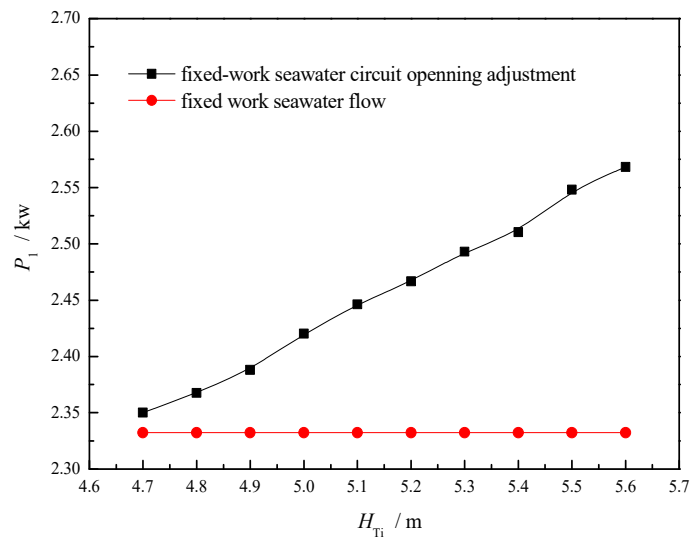

Fig. 7 Input power of supercharger vs. tidal range

It can be seen from the figure that when the tidal range is $4.7 \mathrm{~m}$, the supercharger gains similar power under the two working conditions; as the tidal range increases, the input power of supercharger under the fixed work seawater flow condition is basically not obtained, and the input power of supercharger is increased under the condition of fixedwork seawater circuit opening adjustment. When the tidal range is increased to $5.6 \mathrm{~m}$, the input power of supercharger by the fixed-work seawater circuit opening adjustment is $10.12 \%$ higher than the fixed work seawater flow method. This is because the input power of supercharger is mainly determined by the work seawater flow, the position of the ultrasonic flowmeter of the work seawater loop and the potential energy difference at the inlet of supercharger. After the test bench is built, the potential energy difference of the working seawater circuit is constant, so input power of supercharger is mainly determined by the work seawater flow. as shown in Figure 6, when the opening of work seawater circuit is fixed, the work seawater flow increases as the tidal range increases. Therefore, when the opening degree of the seawater circuit is fixed, the input power of supercharger increases linearly with the tidal range, and when the fixed working seawater flow condition is used, the input power of supercharger is basically not affected by the tidal range.

\subsection{High-Pressure Seawater Flow}

Figure 8 shows the variation trend of high-pressure seawater flow $q_{h p}$ with tidal range $H_{T i}$ under two working conditions. It can be seen from the figure that when the tidal range is $4.7 \mathrm{~m}$, the high-pressure seawater flow is similar under the two conditions; under the condition of fixed work seawater flow, the high-pressure seawater flow does not change with the tidal range, and it is stable at $145 \mathrm{~L} / \mathrm{h}$ approximately. Under the condition of fixed-work seawater circuit opening adjustment, the highpressure seawater flow increases with the increase of tidal range. At 5.6 $\mathrm{m}$, the high-pressure seawater flow under the fixed-work seawater circuit opening adjustment condition is $11.38 \%$ higher than that of the fixed work seawater flow condition. This is because the supercharger is designed for the rated load, so the volume of plunger chamber in supercharger is constant, that is, the volume of high-pressure seawater produced by each movement of the plunger does not change much. Therefore, under the condition of fixed-work seawater circuit opening adjustment, with the increase of tidal range, the high-pressure seawater flow increases with the increase of tidal range. 


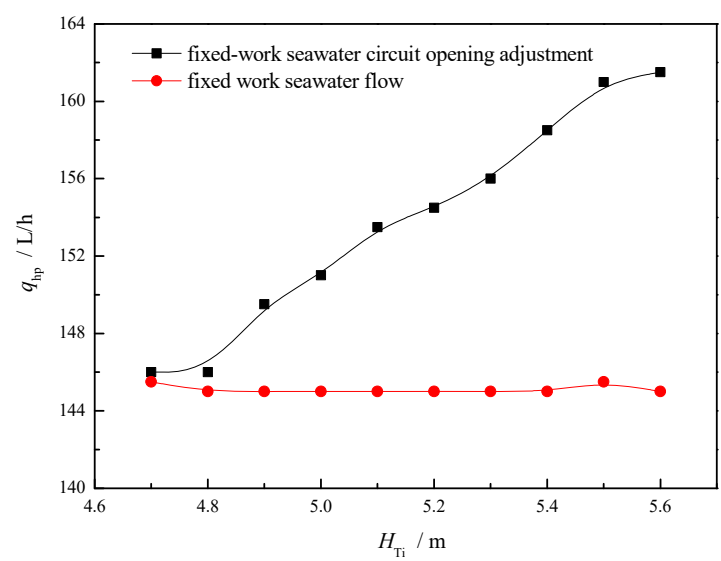

Fig. 8 high-pressure seawater flow vs. tidal range

\subsection{Output Power of Supercharger}

Figure 9 shows the variation of the output power $P_{2}$ of supercharger with the tidal range $H_{T i}$ under two operating conditions.

It can be seen from Figure 9 that when the tidal range is $4.7 \mathrm{~m}$, the output power of supercharger under two working conditions is similar; under the fixed work seawater flow condition, the output power of supercharger is basically unaffected. Under the fixed-work seawater circuit opening adjustment, the output power of supercharger increases with the increase of tidal range. When the tidal range is $5.6 \mathrm{~m}$, the output power of supercharger under the fixed-work seawater circuit opening adjustment is $11.38 \%$ higher than that of the fixed work seawater flow condition. Because the output power of supercharger is mainly determined by the high-pressure seawater flow of supercharger. It can be seen from Figure 8 that under the fixed-work seawater circuit opening adjustment, with the increase of tidal range, the high-pressure seawater flow by supercharger is increased. Under the fixed work seawater flow condition, the high-pressure seawater flow basically does not increase. Therefore, the output power of the supercharger increases with the tidal range under fixed operating conditions of the seawater circuit. The output power of supercharger does not change with the tidal range under fixed work seawater flow conditions.

Therefore, compared with the method that tidal first generates high-pressure seawater after power generation, even if the energy loss of electric power conversion is not considered, the fresh water production and desalination by tidal energy directly method can output more power.

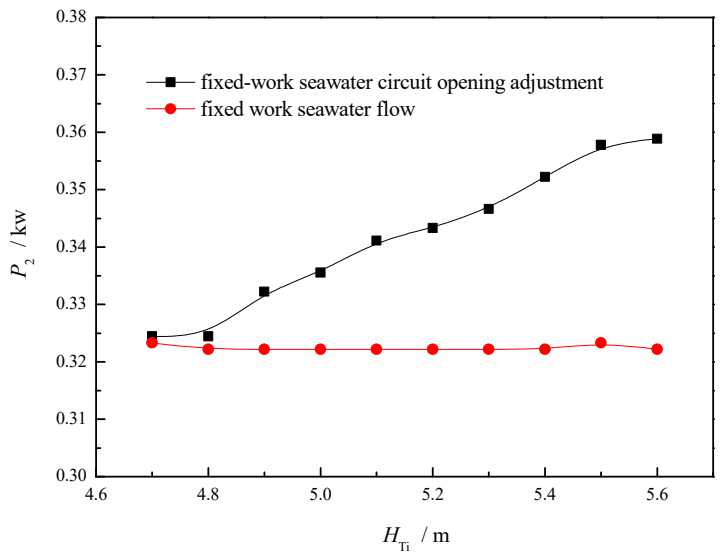

Fig. 9 Output power of supercharger vs. tidal range

\subsection{Efficiency of Supercharger}

Figure 10 shows the variation trend of the energy efficiency $\eta$ of supercharger with the tidal range $H_{T i}$ under two working conditions. It can be seen from the figure that under the fixed work seawater flow condition, the efficiency of supercharger is basically not affected by the tidal range; under the fixed-work seawater circuit opening adjustment, the efficiency of supercharger increases with the increase of tidal range, and there is fluctuation. The efficiency of supercharger is mainly determined by the input and output power of supercharger. It can be seen from Figure 7 and Figure 9 that the input and output power are performed. Under the fixed work seawater flow condition, the input and output power do not change substantially with tidal range. Therefore, in this case, the efficiency of the concentrating supercharger is less affected by the tidal range. Under the fixed-work seawater circuit opening adjustment condition, the input and output power of supercharger increases with the increase as the increase of tidal range. It is necessary to consider the effect of energy loss at different velocities of the supercharger on the efficiency of supercharger. The analysis is because the rotation velocity increases, the rotation loss of supercharger is reduced, the efficiency of supercharger is increased; at the same time, the volume loss of supercharger is increased, and the efficiency of supercharger is decreased, so when the opening adjustment of seawater circuit is fixed, the efficiency of supercharger will show an unstable change with the tidal range, but the overall trend is upward.

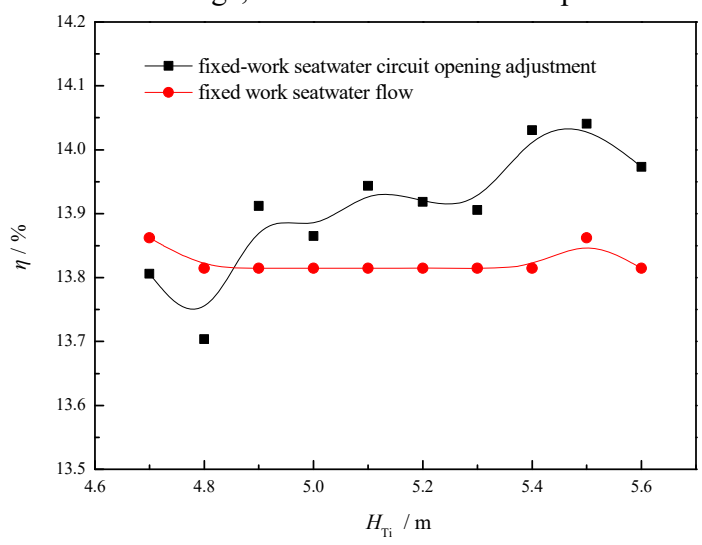

Fig. 10 Efficiency of supercharger vs. tidal range

\section{CONCLUSION}

In the study, aiming at the performance comparison between the fixedfrequency supercharging system and the high-efficient energy-gathering supercharger system, the difference between two methods that directly producing high pressure water by tidal energy to provide reverse osmosis seawater desalination and tidal power was used to generate electricity at first and then producing high pressure water by electric epower to provide reverse osmosis seawater desalination was analyzed. The specific conclusions are as follows:

(1) The supercharger can produce high pressure seawater by pressurizing low-pressure tidal seawater. The boosting pressure is 150 times higher than the initial water head $4 \mathrm{~m}$. It is helpful to produce high-pressure seawater reaching $6 \mathrm{MPa}$ which can be used for the seawater reverse osmosis desalination.

(2) Compared with the traditional tidal energy-driven electricity generation, adaptive-frequency and high-efficient energy-gathering supercharge experimental system that suits tidal changes can increase the use efficiency of tidal energy, make energy-gathering supercharger absorb more tidal energy thus produce more high-pressure water.

(3) With water-head set at $4.7 \mathrm{~m}$, when tidal change increases to $5.6 \mathrm{~m}$ and $6 \mathrm{MPa}$ high pressure water is produced, compared to method of traditional electricity generation, the method of directly producing high pressure water by tidal energy could produce $11.38 \%$ more high pressure water per unit interval.

\section{ACKNOWLEDGEMENTS}

The first and second authors would like to thank the project support of Southern Marine Science and Engineering Guangdong Laboratory (Zhanjiang) (NO.ZJW-2019-01) and Guangdong Science and Technology Department providing the research projects (NO.2017A010104011). 


\section{NOMENCLATURE}

$$
\begin{array}{ll}
H_{\mathrm{Ti}} & \text { the tidal range, }(\mathrm{m}) \\
P_{1} & \text { input power of supercharger, }(\mathrm{kW}) \\
P_{2} & \text { output power of supercharger, }(\mathrm{kW}) \\
q_{\mathrm{hp}} & \text { high-pressure seawater flow, }\left(\mathrm{m}^{3} / \mathrm{h}\right) \\
Q_{\mathrm{Ti}} & \text { work seawater flow rate, }\left(\mathrm{m}^{3} / \mathrm{h}\right)
\end{array}
$$

Greek symbols

$\eta \quad$ efficiency of supercharger

\section{REFERENCES}

R.A. Falconer, J. Xia, B. Lin. The Severn Barrage and other tidal energy options: Hydrodynamic and power output modeling. Environmental hydraulics. Volume 1.2010:13-26. http://dx.doi.org/ 10.1007/s11431-009-0366-Z

Reza Ahmadian, Agnieszka I. Olbert, Michael Hartnett, et al. Sea level rise in the Severn Estuary and Bristol Channel and impacts of a Severn Barrage. Computers \& geosciences, 2014, 66(May):94-105. $\underline{\text { http://dx.doi.org/10.1016/j.cageo.2013.12.011 }}$

G.H. Gao, Roger A. Falconer, B.L. Lin. Modeling effects of a tidal barrage on water quality indicator distribution in the Severn Estuary. Frontiers of Environmental Science \& Engineering, 2013, 7(2):211-218. http://dx.doi.org/10.1007/s11783-012-0464-1

Ng Kim Choon, Thu Kyaw, Oh Seung Jin. Recent developments in thermally-driven seawater desalination: Energy efficiency improvement by hybridization of the MED and AD cycles. Desalination, 2015, SI 359:255-270. http://dx.doi.org/ 10.1016/j.desal.2014.10.025

Lili An. Technology and prospect of Marine energy development in China. Science and Wealth, 2016, 8(4):422-423.

X.P. Zhang. Marine Energy: The Key for the Development of Sustainable Energy Supply [Point of View]. Proceedings of the IEEE, 2012, 100(100):3-5. http://dx.doi.org/ 10.1109/JPROC.2011.2169509

X.P. Zhang. Marine tidal power generation technology. Electrical Manufacturing, 2011(10):30-32.

Y.F. Liu, K.W. Zhao. Study on a multi-effect evaporation desalination unit utilizing solar and tidal energy. ACTA Engergiae Solaris Sinica, 2009, 30(3)
K.W Zhao, Y.F Liu. Theoretical study on multi-effect solar distillation system driven by tidal energy. Desalination, 2009, 249(2): 566-570. http://dx.doi.org/10.1016/j.desal.2009.01.024

Peñate B, García-Rodríguez L. Current trends and future prospects in the design of seawater reverse osmosis desalination technology. Desalination, 2012, 284(1):1-8. http://dx.doi.org/10.1016 /j.desal.2011.09.010

C.K. Gao, Y Zhou, L.F. Liu. Recent development and prospect of seawater reverse osmosis desalination technology. Journal of Ocean Technology, 2016, 35(1):1-14. http://dx.doi.org/ 10.3969/j.issn.10032029.2016.01.001

Berg John L. Wave motor.: US6045339, 2000-4-4.

Kobashikawa A, Fok Y S. Wave energy conversion device for desalination, ETC: US, WO2004007953. 2004-01-22.

Z.J. Zheng. A study on the technology and plant of an innovative tidalpowered reverse osmosis desalination. Zhanjiang: Guangdong Ocean University, 2011.

S.A. Lei. Experimental study on a new desalination device system driven by tidal power directly. Guangdong Ocean University, 2015.

C.M. Ling, Z.J. Zheng, J. Li. Methods and devices for desalination and power generation driven by tidal energy: China, CN 102022251 A. 2011-04-20.

C.M. Ling, Y.F. Wang, C.H. Min, Y.W. Zhang. Economic evaluation of reverse osmosis desalination system coupled with tidal energy. Frontier of Energy, 2018, 12(2): 297-304. https://doi.org/10.1007/s11708-017-0478-2

C.M. Ling, Y.F. Wang, Z.J. Zheng. Research and prospect of desalination technology driven directly by tidal energy // the second annual conference on China's Marine renewable energy development and BBS papers. Beijing: China Ocean Press, 2013:45-49.

Y.F. Wang. Performance study on reverse osmosis desalination system was driven by tidal energy directly. Guangdong Ocean University, 2013.

C.M. Ling, M.F. Chen, Q Xu, J Li. Thermodynamic analysis on plan of seawater pressurization driven by tidal energy. Proceedings of the CSEE, 2015, 35(4): 906-912. http://dx.doi.org/10.13334/j.02588013.pcsee.2015.04.018 